\title{
Abaixo Tordesilhas!
}

JORGE SCHWARTZ

"... fillbos do mesmo continente, quase da mesma terra, oriundos de povos, em suma da mesma rafa, ou pelo menos da mesma formafấ cultural, com grandes interesses comuns, vivemos nos, Latino-Americanos, pouco mais que alheios e indiferentes uns aos outros e nos ignorando quase que por completo."

Palavras de saudação de José Veríssimo a Rubén Darío, por ocasiáo da visita deste à Academia Brasileira de Letras, em 1912.

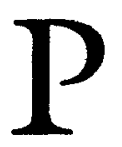

odemos ainda considerar válidas as palavras de Mário de Andrade que, em abril de 1926, afirmou: "no rincáo da Sulamérica o Brasil é um estrangeiro enorme" ? Talvez, se ampliarmos a afirmação e nos perguntarmos qual a posiçáo ocupada pelo Brasil no corpus do discurso crítico literário da América Latina. A retórica continentalista cristalizou e sedimentou cada vez mais o termo América Latina. Mas e o Brasil, gigante adormecido, continua ignorado pela crítica que pretende examinar de forma compreensiva a produçáo literária do continente? Repito aqui as palavras de César Vallejo de 1926 (1): "América Latina. Vedes duas palavras que na Europa têm sido e são exploradas por todos os arrivismos imagináveis: Amćrica Latina. Eis aqui um nome que se leva para baixo e para cima, de um a outro bulevar de Paris, de um a outro museu, de uma a outra revista táo meramente literária quanto intermitente. Em nome da Amćrica Latina conscguem ficar ricos, conhecidos e prestigiosos. A América Latina se presta a discursos, versos, contos, exibiçóes cinematográficas com músicas, bolinhos, refrescos e ânimos dominicais. Em nome da América Latina cresce a rapinagem em torno dos gabinetes europeus que exploram as humildades jactanciáveis da América, com o objetivo de difundir um folclore e uma arqueologia sem pé nem cabeça e de oferecer decorados apotegmas de sociologia barata. Em nome da América Latina se interpreta o 
perigoso papel diplomático da oratória, suscetível de bajulaçôes em banquetes e aniversários, em benefício das rutilantes quimeras convencionais da política européia. Estas duas palavras prestam-se a tudo isto. Delas retiram grande proveito pessoal todos aqueles que nada conseguem fazer por conta própria, exceto se agarrar a seu país de procedência, a antecedentes e a referências de família."

Evidente que aqui Vallejo encontrava-se muito longe de pensar no problema da integração do Brasil à América Latina, mas captou o oportunismo do uso do termo, do qual, possivelmente, foi testemunha na Paris dos anos vinte, quando escreveu este fragmento. Ocorre-me questionar hoje a distância em que o Brasil se encontra dos pressupostos enunciados décadas atrás por Mário de Andrade e César Vallejo.

Sem me deter nas questóes históricas que explicam o fosso cultural existente entre Espanha e Portugal (2), mencionarei a princípio o clássico entrave de caráter lingüístico, que faz do castclhano língua mais acessível ao leitor brasileiro do que o português para o leitor hispanoamericano. Aqui reside uma das barreiras que afastaram o leitor hispânico das obras escritas em português. Salvo em casos excepcionais, os críticos literários do Brasil debruçaram-se com muito maior curiosidade sobre a literatura de seus vizinhos do que aquela manifestada por estes em relaçáo à brasileira. Não encontraremos, até meados do século XX, qualquer intelectual hispânico que tivesse pelas letras do Brasil o interesse abrangente e sistemático que José Veríssimo, Mário de Andrade ou Manuel Bandeira dedicaram às literaturas do continente.

Atento a esse problema, Emir Rodríguez Monegal, que sempre navegou em ambas as águas, afirmou: "os brasilciros cultos freqüentam mais assiduamente e com maior proveito a literatura hispano-americana que seus colegas hispânicos a brasileira, devido à preguiça (ou incapacidade) de verificar se realmente o português é tão difícil de sc ler (3).

Exemplo disso é Alfonso Reyes, que pouco aproveitou de sua experiência como diplomata no Brasil, no sentido de um intercâmbio mais próximo com a literatura brasileira. Durante os quatro anos em que dirigiu no Rio de Janeiro o Correo Literario de Alfonso Reyes publicado integralmente em espanhol, dedicou ao Brasil reduzidíssimo espaço no erudito tablóide. $O$ mesmo pode-se dizer de Gabriela Mistral em semelhante missão. Suas experiências não passaram de anedóticas e pessoais, tendo o Brasil pouco influenciado suas reflexóes. Mesmo assim, houve casos excepcionais, como o diálogo implícito de Sor Juana com o Padre Vieira, por exemplo, revelando um dos aspectos mais sagazes e polêmicos da poetisa mexicana; a eviidente influência de Gôngora e 
Quevedo na obra de Gregório de Matos, o maior poeta barroco brasileiro; ou a presença da América Latina n'O guesa errante, de Sousândrade. Estes escritores, porém, não estavam preocupados $\mathrm{cm}$ criar um sistema literário (como bem aponta Antonio Candido, este será um processo que ocorrerá apenas no século XIX). Tampouco intercssa, no momento, analisar estes escassos exemplos de intertextualidade literária entre as literaturas de língua espanhola e portuguesa. $O$ que procuramos é uma reflexão crítica capaz de, ao considerar a América Latina, nela incluir devidamente o Brasil. Deve-se ainda atentar para o fato de, a partir de 1850, quando começam as tentativas de se distinguir uma América Latina de uma América Saxônica, $o$ Brasil ser uma monarquia cercada de repúblicas. Assim, além das diferenças lingüísticas e culturais, havia um imenso fosso político, uma vez que grande parte dos países de fala espanhola começaram seu processo de independência nas primeiras décadas do século XIX acompanhados, quase sem exceção, de movimentos de afirmação de uma língua nacional.

Enquanto conceito aplicado a questóes tanto políticas como literárias, o termo América Latina surge pela primeira vez em 1836, em artigo de Michel Chevalier, retomado com vigor pelo escritor e diplomata colombiano José María Torres Caicedo (1827-1889). Torres Caicedo foi defensor ardoroso e o maior divulgador do termo na segunda metade do século XIX, sobretudo por seu livro Unión latinoamericana, de 1865. Sua obra foi resgatada do esquecimento pelo venezuelano Arturo Ardao que, ao publicar em 1980 o fundamental Génesis de la idea y el nombre de América Latina, faz a defesa das idéias de Caicedo, empenhando-se, entre outras coisas, em desfazer o engano - hoje quase um mito - de o termo América Latina ter sido cunhado e difundido pelos ideólogos de Napoleão III, como justificativa da invasáo do México (4). Ainda em 1972, no extraordinário América Latina en su literatura, o organizador César Fernández Moreno encontrou dificuldades para conceituar o termo: "América Latina, entidad todavía no definida, pero que presenta a simple vista la consistencia de lo real" (5).

$\mathrm{Na}$ vertente hispânica, mencionarei as obras de Arturo TorresRíoseco (Nueva bistoria de la gran literatura iberoamericana, 1945) e de Pedro Henríquez-Ureña (Historia de la cultura en la América Hispánica, 1947). Esses dois trabalhos, sem sombra de dúvida, são pioneiros. Em ambos nota-se abordagem que privilegia a diacronia, na qual prevalece a intenção totalizante. $O$ trabalho de Torres-Ríoseco dedica à literatura brasileira um capítulo em separado, mas pelo menos não a ignora. Já o crítico dominicano Pedro Henríquez-Ureña empreende extraordinário esforço integrador, chamando nossa atenção a definição com que abre sua obra: "A América Hispânica, que correntemente se 
designa com o nome de América Latina, abarca hoje dezenove naçóes. Uma é de língua portuguesa, o Brasil, a de maior extensão territorial. Dezoito são de língua espanhola" (p. 7). As palavras de Pedro Henríquez-Ureña podem dar a impressáo de que se opunha ao ideário panamericanista ou latino-americanista, pois, ao ser por fim integrado ao panorama continental, o Brasil o é sob a rubrica do hispanismo. $\mathrm{Na}$ realidade, ele está fazendo uso da acepção mais tradicional do conceito romano de Hispania, equivalente hoje a Iberoamérica (6).

Essas iniciativas terão continuidade décadas mais tarde, nas obras de Emir Rodríguez Monegal e Ángel Rama, que formulam um projeto capaz de integrar o Brasil aos parâmetros continentais. Os dois grandes críticos uruguaios contavam inicialmente com a vantagem de viver em um país limítrofe. Dadas as extraordinárias diferenças que os distinguiam, é surpreendente terem sido eles os críticos hispano-americanos contemporâneos que mais se aproximaram da literatura brasileira. Monegal passou grande parte de sua juventude em terras brasileiras, o que facilitou o seu acesso à língua. $O$ caráter integrador da crítica do autor é evidente em quase toda a sua obra, o que se nota com toda a clareza na relaçáo de articulistas do famoso Mundo Nuevo, publicado nos anos sessenta e, sobretudo, na Borzoi Anthology of Latin American Literature. Quanto a Ángel Rama, seu extraordinário projeto editorial - a Biblioteca Ayacucho - foi concebido desde o início com o propósito de, entre outras coisas, incorporar de forma significativa na coleçáo a produçáo literária do Brasil. Embora Rama tivesse chegado à literatura brasileira posteriormente a Monegal, em 1954 já há registro de um primeiro artigo sobre a Nueva poesía brasileña (7). Ángel Rama é também considerado como um dos primeiros, senão o primeiro, a desenvolver, sob a perspectiva comparatista com o movimento de vanguarda argentino o martinfierrismo - o modernismo de 22 , em artigo com o feliz título de Las dos vanguardias latinoamericanas (8).

O mais importante, agora, é tornar conhecido aqueles críticos que, como dizia Lezama Lima, lançaram "uma ponte, uma grande ponte que não se vê" [un puente, un gran puente que no se le ve].

Nas primeiras décadas deste século, José Veríssimo foi o intelectual brasileiro melhor informado sobre as questóes sociais, históricas e literárias da América Latina. Embora contemporâneo de Manoel Bonfim e Sílvio Romero (os quais mantiveram polêmica feroz através de livros com o mesmo título - A América Latina -, publicados em 1905 e 1906 respectivamente), seu discurso, apesar dos poucos anos que o separavam dos livros daqueles autores, deles divergiu em todos os sentidos. Seu conhecimento histórico da evoluçáo política de países como 
Argentina, México, Venezuela e Paraguai, assim como sua aguçada consciência política, sempre o levaram a marcar posição contra a Doutrina Monroe, mantendo seu discurso sempre empenhado c veemente, sem contudo resvalar para o impressionismo da época. Veríssimo também se distinguiu de seus antecessores por deixar de lado teorias racistas ou evolucionistas nas quais Bonfim e Romero ainda se apoiavam. Dos intelectuais do início deste século, foi ele sem dúvida quem mais detidamente acompanhou a literatura dos países hispânicos. Já falava em literatura latino-americana com visáo continentalista que assumia abertamente a retórica do nós, latino-americanos e, de forma pioneira, chamava a atenção para os processos de mútua exclusão vigentes entre o Brasil e seus vizinhos: "Tive já ocasião de confessar a minha ignorância das literaturas hispano-americanas. Creio que sem injustiça, associei ncla a generalidade dos meus companheiros, ainda que homens de letras. Disse também que essa ignorância é recíproca, isto é, que os outros hispano-americanos (os outros escrevo porque hispano-americanos também somos nós, pois Portugal é Espanha) igualmente nada sabem das nossas letras" (9).

Dos sete artigos de Veríssimo sobre literatura recolhidos por João Alexandre Barbosa em Cultura, literatura e politica na América Latina, três referem-se à literatura argentina. Seja pela proximidade geográfica, seja pela qualidade de sua produçáo intelectual, a Argentina foi o país que maior interesse despertou no brasileiro. Neste sentido, não poupou elogios a Bartolomé Mitre e a Paul Groussac, este último diretor da Biblioteca Nacional de Buenos Aires e editor dos Anales de la Biblioteca. Também foi ávido leitor de José Ingenieros e dos mais importantes pensadores e escritores argentinos do século XIX. Coube a José Veríssimo registrar as traduçóes para o espanhol, de Inocéncia, de Taunay; Canaã, de Graça Aranha; e Esaú e Jacó, de Machado de Assis, realizadas por Roberto Payró no início do século. É espantoso o grau de informação e atualização de Veríssimo. Somente Mário de Andrade, Brito Broca e Manuel Bandeira foram capazes de atualizar tal visão nas décadas seguintes.

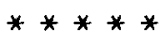

Ávido leitor, bibliófilo incansável e copioso correspondente, Mário de Andrade sempre fez questáo de manter-se informado a respeito do que se passava na literatura e nas artes dos países vizinhos, sobretudo da Argentina. Imbuído talvez de ideais anarquistas e confratcrnização global, em nome de valores universais Mário de Andrade refutava qualquer defesa do nacionalismo. Por isso, rebelou-se igualmente contra a 
idéia de América Latina: "Mas, todo e qualquer alastramento do conceito de pátria que não abranja a humanidade inteira, me parece odioso. Tenho horror a essa história de America Latina muito agitada hoje em dia" (10). Apesar de tal afirmaçáo, Mário de Andrade foi um dos primeiros críticos empenhados nessa visão integrativa. Em seus surpreendentes ensaios sobre literatura argentina, publicados em 1927 e 1928 no Diário Nacional de Săo Paulo, percebe-se seu conhecimento sobre toda a produçáo literária argentina da época. É ele quem, de certa forma, dá continuidade ao pensamento integracionista de José Veríssimo, o que lhe permitiu, inclusive, emitir juízos precoces e corretos como "Borges me parece a personalidade mais saliente da geraçáo moderna argentina" (11). Nada porém o atraía mais que a comparaçăo Brasil/Argentina, São Paulo/Buenos Aires. Interessava a Mário fazer um trabalho comparativo de culturas, quase que uma tese de antropologia social. Insistiu em diferença baseada na psicologia social do brasileiro, por oposição à do argentino, do peruano ou do mexicano. Tampouco descuidou das diversidades geográficas, mostrando as profundas diferenças entre os efeitos, no imaginário cultural, de lugar tão estéril como a Patagônia, e os da luxuriante regiăo amazônica, base de inspiraçăo de Macunaima. Além disso, Mário de Andrade examinou os aspectos que definem as falas brasileira e argentina por oposiçáo às normas das respectivas academias de Lisboa e Madri, tudo isto para definir um perfil nacional, uma identidade brasileira ou argentina. Suas consideraçōes literárias revelam um escritor muito bem informado sobre a produção intelectual no país limítrofe.

Leitor voraz e crítico literário, tendo na crônica seu gênero predileto, Brito Broca publicou em 1944, pela editora Guaíba, de Curitiba, uma coletânea de sete ensaios sob o título de Americanos (primeira série). Atualmente, na coleção Brito Broca da Unicamp (no Centro de Documentaçáo Cultural Alexandre Eulálio - CEDAE) existe uma segunda série, composta de seis artigos (que não se sabe se organizados pelo próprio Brito Broca ou por Alexandre Eulálio). Além desses, encontram-se de forma esparsa cerca de doze outros artigos de temática afim, publicados nos anos quarenta sob a rubrica de Literatura latinoamericana e, posteriormente, Literatura panamericana, nos jornais Cultura e Política, e A Manbã, do Rio de Janeiro. Interessa saber que a visão continental de Brito Broca é extensiva, incluindo autores como Walt Whitman, Fenimore Cooper e Mark Twain, apesar de a tônica recair sobretudo nos hispano-americanos. A aventura literária de Brito Broca é um verdadeiro exercício de literatura comparada: prevalece o tom impressionista, descritivo e anedótico; na maior parte das vezes sua intuiçáo lhe permite aproximaçóes certeiras entre as nossas literaturas. 
Assombra o número de leituras realizadas pelo crítico e, depois de José Veríssimo, é Brito Broca quem reivindica de forma mais explícita uma política cultural integracionista no continente.

$\mathrm{Na}$ leitura dos diversos autores, Brito Broca privilegiou, como forma diferenciadora de expressão, mais o espaço geográfico do que a linguagem. Isso explica seu fascínio pelo pampa argentino nos textos de W. H. Hudson, Ricardo Güiraldes e Benito Lynch; pela selva colombiana em La porágine, de José Eustasio Rivera; ou pelo sertão colombiano em María, de Jorge Isaacs. Essa mesma predileção pela geografia o levou a descrever a produçáo literária latino-americana a partir de Paris (A sedufão de Paris), ressaltando a crônica do guatemalteco Enrique Gómez Carrillo e contrapondo-o ao nosso João do Rio: "Há, porém, mais brilho, colorido e vibração no estilo do João do Rio, indiscutivelmente mais artista do que Gómez Carrillo".

Ao rastrear o interesse que os intelectuais brasileiros tinham pelas letras hispano-americanas, Brito Broca destacou o papel dos modernistas, especialmente Ronald de Carvalho nos poemas de Toda América. Conforme nos informa o crítico, o primeiro romance argentino traduzido para o português foi $O$ mal metafísico, de Manuel Gálvez. Também ressaltou a importância de Monteiro Lobato na difusão das letras hispano-americanas, por intermédio da Revista do Brasil e da Biblioteca Sul-Americana, na qual foram publicados Facundo, de Sarmiento, e Nacha Regrules, de Gálvez [incluir Lobato, Revista do Brasil, 1922]. Aliás, em 1947, o mesmo Monteiro Lobato, sob o pseudônimo de Miguel P. García, publicaria em Buenos Aires o romance didático-político destinado à promoçáo do plano qüinqüenal de Perón, La nuepa Argentina. Brito Broca também deixou registradas as visitas ao Brasil de Miguel Ángel Asturias e Horacio Quiroga. Este último, autor de Cuentos de la selva e Anaconda, ao ser homenageado em São Paulo por vários escritores, foi alvo de engraçada saudaçáo de Lobato, rememorada por Brito Broca: "[Lobato] chamou-o de amigo das serpentes, o maior cobrófilo até então conhecido. Vivendo entre elas, no território das Missões, criou-lhes tal amor, que em São Paulo logo ao chegar, sua primeira pergunta foi: Onde fica o Butantã? Conhecedores desta sua mania dizia Lobato - tencionávamos organizar-lhe uma festa serpentina. Mesa em coleios de sucuri, garçons urutus, canja de cascavel, linguiça de caninana, omelete de ovos de jararaca e várias garrafas de soro anticrotálico.

Da maior importância foi a viagem empreendida por Brito Broca a Buenos Aires e La Plata em 1947. Dela resultaram as vivazes entrevistas com Roberto Giusti, Eduardo Mallea e Benito Lynch. Embora as 
leituras do crítico revelem predominância de acertos literários, sua apreciaçáo de Jorge Luis Borges aparece diluída e de forma indireta. Assim como acontecera com muitos argentinos, também ele só tomou conhecimento da obra borgiana por intermédio da crítica francesa: "Na Argentina, atualmente, há um escritor originalíssimo e de grande mérito, cuja obra vem encontrando ressonância na França: Jorge Luis Borges... No Brasil, quem o conhece? Quem o lê? Com exceçáo do meu amigo Alexandre Eulálio, cada vez mais apaixonado pelo requinte espiritual e humor pótico de livros como Historia da infamia, creio que apenas uns dois ou três extravagantes, pois, continua a ser mais ou menos uma extravagância entre nós alguém interessar-se por escritor hispano-americano".

Causa estranheza que, vinte anos após Mário de Andrade ter apresentado Borges aos brasileiros em artigos no Diário Nacional, Brito Broca tenha excluído Mário do seu panorama de latino-americanistas e redescoberto Borges via Europa. Na criativa leitura que Davi Arrigucci Jr. faz das relaçóes Brito Broca/Alexandre Eulálio/Borges, acertadamente ressalta a " [incapacidade] de um reconhecimento crítico adequado do grande escritor e de sua real posiçáo diante da tradição de onde surge", chamando esse diálogo de "conversa de fantasmas" (12). De fato, quando Brito Broca visitou Buenos Aires, Borges não só já havia publicado Ficciones, como vários livros de poesia e ensaios.

$* * * * *$

O caminho aberto por José Veríssimo, retomado dez anos mais tarde por Mário de Andrade e trilhado de maneira fecunda por Brito Broca, chegará a um momento de extraordinária expressividade em Manuel Bandeira, destacando-se de várias maneiras dos anteriores, em especial pelo caráter profissional dado aos seus estudos de literatura hispano-americana. Bandeira foi professor catedrático dessa matéria na Universidade Federal do Rio de Janeiro no período de 1943 a 1956 e o primeiro a divulgar, no Brasil, a literatura hispano-americana de forma sistematica. Dele, merecem destaque a Literatura hispano-americana, em duas ediçóes (1949 e 1960), e as Trts conferencias sobre cultura bispano-americana (1959). Bandeira também conseguiu cruzar a grande ponte ao publicar, em 1951, pela editor mexicana Fondo de Cultura Económica, seu Panorama de la poesía brasileña.

Embora denominado Literatura bispano-americana, o livro é mais que isso. Estamos frente a vasta leitura da cultura da América Latina desde as manifestaçóes culturais pré-colombianas até os poetas e ensaís- 
tas contemporâneos a Bandeira. É admirável perceber que, apesar de os 27 capítulos serem organizados cronologicamente, esta cronologia subordina-se a um gosto muito individualizado e capaz de deter-se nos assuntos mais diversos como Os primeiros colégios e Universidades: $a$ introduçáo da imprensa, ou capítulos dedicados integralmente a cronistas, poetas, dramaturgos e ensaistas de sua predileção (como Garcilaso de la Vega, Sor Juana Inés de la Cruz, Juan Ruiz de Alarcón, Andrés Bello ou Rod6). Nesse sentido, Bandeira detém-se em todos os gêneros literários que constituíram a literatura hispano-americana - desde as narrativas do descobrimento, passando pelo barroco e pela poesia modernista, até chegar a crítica contemporânea. Se o trabalho de Bandeira é erudito, assustando até pelo número de leituras e informaçóes, nāo chega a ser acumulativo, estéril ou cansativo, como sói acontecer com este tipo de livro, próximo às vezes do manual literário. Sua crítica é extremamente opinativa e à distância percebemos que dificilmente comete erros qualitativos em sua avaliação. Por exemplo, ao tratar dos barrocos, exalta a poesia de Sor Juana. Em contraposição, afirma Bandcira que "a péssima qualidade dos gongoristas mexicanos está fartamente documentada no Triunfo Parténico de Carlos de Singüenza y Góngora ... Nada vale a sua poesia" (13). Seu gosto pelo comparatismo e por uma política literária latino-americanista já aparece na abertura do capítulo dedicado à Literatura do Descobrimento e da Conquista: "assim como a carta de Pero Vaz de Caminha inicia a literatura de língua portuguesa no Brasil, inauguram as cartas-relaciones de Colombo a literatura de língua espanhola na Hispano-América" (14). De forma análoga, aproxima o poeta $\mathrm{Ca}$ viedes a Gregório de Matos: "Caviedes foi a encarnaçáo do espírito limenho; tornou-se a Bôca do Inferno da Sociedade de Lima pelas suas sátiras desabusadas e mordazes" (15). Outro dos seus momentos de atrevimento crítico é considerar Herrera y Reissig de melhor qualidade que Rubén Darío: "deu o Uruguai o seu maior poeta, uma das vozes mais originais da poesia hispano-americana, por alguns mesmo considerada substancialmente mais forte e mais genuína que a do próprio Darío" (16).

Também nos inteiramos, através de Bandeira, que o importante romancista argentino do século XIX, José Mármol, autor de Amalia, viveu dois anos, entre 1843 e 44, no Rio de Janeiro: "Aqui escreveu grande parte do longo poema El peregrino, espécie de Child Harold americano, com um canto integralmente dedicado ao Brasilu, rememora Bandeira (17). Outra presença surpreendente no Rio de Janeiro do século XIX é a do poeta e jornalista argentino Carlos Guido y Spano: (18) "Aos treze anos veio para o Rio de Janeiro [em 1842], onde o pai servia como representante diplomático. Guido y Spano conseguiu 
dominar o idioma português, para o qual traduziu o Raphael de Lamartine. No Rio tomou parte do movimento romântico, e do seu prestígio em nosso meio literário se pode julgar pelo fato de o nosso Gonçalves Dias, já célebre e quatro anos mais velho do que ele, lhe ter pedido um prefácio para os Últimos cantos."

À diferença dos críticos anteriores, Bandeira inclui no seu vastíssimo repertório as vozes femininas mais importantes de hispano-américa. Cabe a Bandeira o mérito de ter sido o primeiro a divulgar de forma muito expressiva o nome de Sor Juana Inés de la Cruz, décadas antes de ela tornar-se moda feminista. Aliás, ele já a chama em 49 de monja feminista (p. 63). Por proximidade ou não a Gabriel Mistral, de quem foi amigo pessoal durante sua permanência oficial no Rio de Janeiro, Bandeira inclui as vozes mais expressivas da poesia feminina das primeiras décadas do século: a própria Mistral, Delmira Agustini, Maria Eugenia Vaz Ferreira, Juana de Ibarbouru e Alfonsina Storni.

Os autores comentados por Bandeira mostram sua proximidade com toda e com a melhor poesia de vanguarda do continente. Nesse sentido, aparecem mencionados importantes poetas nicaragüenses (Salomón de la Selva, José Coronel Urtecho, Pablo Antonio Cuadra), Vallejo, Huidobro, Neruda, Carrera Andrade. Bandeira também se aproxima da poesia afro-americana, nas vozes de Nicolás Guillén, Emilio Ballagas e Palés Matos.

Bandeira conhece a geração martinfierrista, mencionando os manifestos e revistas, assim como a importantíssima geração mexicana em torno da revista Contemporáneos. Dois pecados, entretanto: não estabelece a relação entre esses movimentos com a Semana de 22 , da qual foi protagonista; e praticamente ignora a presença de Borges, que já publicara vários livros de poesia, livros de ensaios e Ficciones e $E l$ aleph, o que não se justifica. Bandeira era muito próximo de Mário de Andrade e de Alfonso Reyes; ambos, por sua vez, conhecedores do escritor argentino. Aliás, a única referência a Borges é estranha (19): "Um jovem poeta argentino que entáo vivia em Madri, Jorge Luis Borges, $\mathbf{n}$. em 1900, regressando a Buenos Aires em 1921, começou a bandeirizar o ultraísmo entre os seus compatriotas..." (p. 198-199).

Se por um lado surpreende a pouca atenção dada a Borges, por outro agrada o destaque dado a Mariátegui: "A América perdeu prematuramente em José Carlos Mariátegui (1891-1930) uma de suas mais fortes e nobres personalidades" (p. 207).

Diferentemente de José Veríssimo, Mário de Andrade e Brito Broca, Bandeira não privilegia os argentinos. Nem por isso, eles deixam 
de estar devidamente representados e equiparados na descrição continental empreendida pelo autor de Libertinagem.

A cátedra de Manuel Bandeira na UFRJ foi sucedida por Bella Jozef, autora da Historia da literatura bispano-americana, (20) já com várias reediçóes e, hoje, texto essencial para os estudantes brasilciros de literatura hispano-americana.

Raúl Antelo pertence à nova geração de críticos, empenhados, como eu, na eliminação da linha de Tordesilhas. Argentino residente no Brasil, bilíngüe e bicultural, destaca-se em sua obra o livro publicado em 1986, dedicado às leituras que Mário de Andrade fez dos hispano-americanos - Na ilha de Marapatá: Mário de Andrade lé os bispano-americanos. É uma espécie de radiografia ideológica de ćpoca, a partir das leituras, anotaçóes marginais, recortes e correspondência de Mário de Andrade com o mundo hispano-americano. Antelo demonstra inclusive como o processo seletivo do escritor paulista influenciou sua produção poética. Longe de limitar-se ao material hispânico na obra de Mário de Andrade, Antelo nos mostra a presença brasileira na América Hispânica como, por exemplo, duas raras resenhas de Borges, de 1933: uma de Versos, de Paulo de Magalháes, e outra, Noroeste e outros poemas do Brasil, de Ribeiro Couto, assim como o artigo de María Rosa Oliver, publicado em Sur, por ocasiáo da morte de Mário de Andrade. Esse trabalho tem continuidade no ensaio Macunaima: apropriafão e originalidade (21), para a edição crítica de Macunaima da coleção Arquivos, em que Antelo mostra com erudiçáo as raízes latino-americanas do romance.

Escapa à simples categorizaçáo a obra de Davi Arrigucci Jr., sobretudo seu brilhante trabalho sobre Julio Cortázar - $O$ escorpião encalacrado, de 1973 -, inacessível ao público hispano-americano não tanto pelo enigmático título, mas pela fatalidade de ter sido escrito em português.

As duas grandes matrizes do discurso integrador de culturas são hoje representadas no Brasil por Antonio Candido e Haroldo de Campos. Ambos incorporaram às suas reflexóes a produçáo literária e crítica da América Hispânica. Em seu clássico artigo Literatura e subdesenvolvimento, de 1972, Antonio Candido tece relaçốcs cujos parâmetros básicos são os vínculos de dependência cultural, a consciência do subdesenvolvimento e a importação de modelos, para finalmente privilegiar o regionalismo e sua superação por meio do super-regionalismo. Sua crítica, como definida por Davi Arrigucci Jr., "defende e demonstra pela prática analítica, com a clareza de sempre, a legitimidade do ponto de vista histórico no estudo da literatura, sem que isto signifique o abandono da perspectiva estética. Esta não sc confunde, para ele, com qual- 
quer formalismo redutor, e procura dar conta da obra como realidade própria, sem contudo perder de vista a realidade humana, psíquica e social, com que a primeira se relaciona, sem a ela tampouco se reduzir" (22).

Além da produção crítica propriamente dita, Antonio Candido destaca-se por ter privilegiado, nas últimas décadas, política cultural integracionista, através de vários projetos que mencionarei adiante.

Já Haroldo de Campos privilegia o topos frente ao chronos. Inspirado em Eliot, Jakobson e Borges, sua construção teórica baseia-se na poética sincrônica (23). Em Superaçáo das linguagens exclusivas, de 1972, ampliado e publicado no Brasil em 1977 como Ruptura dos gtneros na literatura latino-americana, o fundador da Poesia Concreta cruza fronteiras a partir de categorias estéticas: a fusão poesia/prosa (Lezama Lima, Clarice Lispector, Guimarães Rosa, Severo Sarduy), a metalinguagem (Machado de Assis, Macedonio Fernández, Jorge Luis Borges, Julio Cortázar), ou uma linhagem poética que aponta para a concretude do poema (Huidobro, Paz, Parra; Drummond, João Cabral e os próprios poeta concretos). Enquanto transcriador, Haroldo de Campos representa uma das vertentes mais fecundas e criativas neste diálogo: Sor Juana, Vallejo Cortázar e o formidável Transblanco de Octavio Paz. Incorporados ao seu paideuma, encontram-se ainda Huidobro, Girondo, Lezama Lima e Sarduy.

Gostaria agora de mencionar alguns projetos que fazem da América Latina um corpus cultural unificado, nele incluído o Brasil.

Em primeiro lugar, a coleção Literatura Latinoamericana de Casa de Las Américas (Cuba), iniciada em 1963, tentando de forma ostensiva e pioneira essa visáo integrativa. O primeiro título, justamente, é $\mathrm{Me}$ mórias póstumas de Brás Cubas, de Machado de Assis, traduzido por A. Alatorre. Dos 134 títulos até hoje publicados, 33 pertencem ao Brasil (24).

Em segundo lugar, o já citado América Latina en su literatura, publicado em 1972 com patrocínio da Unesco, obra precursora da crítica latino-americana como perspectiva totalizante de culturas. Em forma de ensaios organizados tematicamente, nele figuram doze países totalizando vinte e sete contribuiçōes. Nas várias reuniōes preparatórias iniciadas em Buenos Aires, em 1969, o Brasil foi representado por Sérgio Buarque de Holanda e Afonso Arinos de Melo Franco. Em consequiência, foram incluídos no volume quatro intelectuais brasileiros de primeira grandeza: Antonio Houaiss, que tratou da pluralidade lingüística dos países ibéricos; Haroldo de Campos, com o mencionado artigo 
Superación de los lenguajes exclusidos; Antonio Candido, com o já clássico Literatura e subdesenvolvimento; e José Guilherme Merquior, que estudou o papel do escritor no continente desde os tempos coloniais. Pela primeira vez, um projeto trouxe proposta coerente para a queda do muro de Tordesilhas, o que aparece de forma explícita na introduçáo de César Fernández Moreno: "Es por eso que hemos solicitado a todos los que colaboran en el proyecto que traten de encarar sus trabajos a partir de ese concepto de unidad. Satisfacer tal pedido ha presentado, es claro, serias dificultades, dada la tradicional falta de comunicación que ha habido entre los países de América Latina, sobre todo en lo que se refiere a sus dos regiones linguísticas: hay en América Latina una enorme zona, casi un continente de por sí, qúe habla portugués, y que no siempre tiene una visión completa de lo que se produce en la zona que habla español, y viceversa" (25).

Como resultado dessa proposta unificadora e interativa, os quatro brasileiros lançaram olhar abrangente sobre as literaturas e linguagens americanas. Salvo algumas exceçóes, o mesmo não se pode dizer de seus colegas hispano-americanos com relação às brasileiras.

Em terceiro lugar pode ser citada a Biblioteca Ayacucho, concebida por Ángel Rama e iniciada em 1976. Com a assessoria de Antonio Candido, tal coleção, inspirada talvez no modelo de Casa de las Américas, incorporou de forma significativa a produçăo literária do Brasil. As obras traduzidas para o espanhol constituem via de acesso ao interessado na litcratura e cultura brasilciras, assim como os textos introdutórios o são à crítica literária brasilcira.

Um quarto projeto editorial de caráter muito diferenciado trata da Coleção Arquivos, dirigida por Amos Segala, também patrocinada pela Unesco. Oito países signatários apóiam o projeto. Trata-sc de ediçóes críticas nas línguas originais, portanto com perfil inteiramente diferente do de Casa de las Américas ou do da Biblioteca Ayacucho. Além de se buscar o estabelecimento definitivo do texto, com todas as suas variantes, as obras são publicadas com abundante material crítico. Participam do projeto vinte e dois países, inclusive Dominica, Jamaica, Guiana e Haiti. Dois fatos merecem especial atenção: primeiro, a Coleçăo Arquivos, assirn como a Casa de las Américas, incluem no seu conceito de América Latina países do Caribe de expressão francesa e inglesa. Segundo, o Brasil está representado com o mesmo número de volumes que a Argentina e o México, doze no total; até o momento saíram três: $M a-$ cunatma, de Mário de Andrade; $A$ paixíio segundo G. $H$., de Clarice Lispector; e Cronica da casa assassinada, de Lúcio Cardoso. Dé todos os 
projetos já realizados, a coleção Arquivos é o mais ambicioso e completo, contando com o maior número de colaboradores.

Importante ainda mencionar dois projetos no prelo. O primeiro, idealizado anos atrás por Ángel Rama e Antonio Candido, trata de três volumes programados para a coleção América Latina: cultura, linguagem e literatura. Concebido originalmente como uma história da literatura composta de artigos organizados em três volumes, conta com um terço dos ensaios em língua portuguesa. Atualmente, os responsáveis pelo projeto são Ana Pizarro para a parte hispânica; Antonio Candido, Alfredo Bosi e Roberto Schwarz, para cada uma das partes dedicadas ao Brasil.

O último projeto é o Delal: Diccionario de las letras de América Latina, organizado por Nelson Osório, verdadeira enciclopédia com 2200 verbetes, escritos por especialistas de vários países, no qual o Brasil aparecerá devidamente representado.

Cabe por fim observar que a obra de Torres-Ríoseco, Casa de las Américas, a Biblioteca Ayacucho, a antologia Borzoi, a Coleção Arquivos e o dicionário Delal colocam o Brasil junto a Hispano-América. E entenda-se junto em sentido literal: o Brasil ao lado da América Hispânica. Talvez seja um desejo utópico querer uma reflexão conjunta, entrelaçada. Já o fizeram alguns dos críticos mencionados neste texto. De qualquer forma, salta à vista o fato de até hoje náo ter sido publicado em espanhol um clássico como a Formafão da literatura brasileira, de Antonio Candido, nem um único livro de ensaios de Haroldo de Campos. É como se o Brasil, para os leitores hispano-americanos, só interessasse enquanto verbete em obras de referência. Sc é verdade que o $\mathrm{V}$ Centenário da chegada dos portugueses ao Brasil será comemorado no ano 2000, fica o desejo de que náo tenhamos de esperar até o século XXI para nossos vizinho chegarem com as caravelas às nossas bibliotecas.

\section{Notas}

1 Favorables Parts Poemas2 (out. 1926), p. 14.

2 Já em 1914, ao resenhar o livro de Oliveira Lima América Latina e América Inglesa, José Veríssimo observava: "Não há na conquista portuguesa da América nada comparável à espanhola do México, do Peru ou do Chile. As próprias lutas civis aqui náo tiveram jamais - $\mathrm{e}$ ainda bem - a repetiçāo, a duraçáo, o encarniçamento de iguais lutas nas colônias espanholas, antes ou depois da independência" .

3 Emir Rodríguez Monegal. Mário de Andrade/Borges. Um dialogo dos anos 20. São Paulo, Perspectiva, 1978, p. 12. 
4 Arturo Ardao. Génesis de la idea y el nombre de America Latina. Caracas, Centro Rómulo Gallegos, 1980. Todas as minhas informaçōes foram baseadas neste excelente estudo, que me foi indicado por Antonio Cornejo Polar.

5 America Latina en su literatura. México, Siglo XXI/Unesco, 1972, p. 9.

6 Neste sentido, assinala Arturo Ardao, op. cit.: "En acepción amplia, que tiene por fundamento la antigua aplicación a toda la península ibérica del nombre romano Hispania, Hispanoamérica - con sus variantes América Hispana y sobre todo América Hispánica - abarca al mismo ticmpo las Américas Española y Portuguesa: los países americanos de origen español y el Brasil" (p. 21).

7 Em El Nacional, 17 maio 1954.

8 Maldoror 9 (1973), p. 58-64.

9 José Veríssimo. Cultura, literatura e politica na América Latina. Organização e apresentação de João Alexandre Barbosa. São Paulo, Brasiliense, 1986, p. 74.

10 Em Mário de Andrade/Borges, p. 74.

11 Op. cit., p. 101.

12 Davi Arrigucci Jr., "Conversa entre fantasmas (Brito Broca e os Americanos), em Remate de Males 11. Campinas, Unicamp, 1991, p. 71.

13 Manuel Bandeira. Literatura bispano-americana. Rio de Janeiro, Fundo de Cultura, 1960 (1 ${ }^{\text {a }}$ ed. 1949).

14 Op.cit., p. 15.

15 Op. cit., p. 65.

16 Op. cit., 166-167.

17 Op. cit., p. 95.

18 Op. cit., p. 97.

19 Op. cit., p. 198-199.

20 Petrópolis, Vozes, 1971.

21 Em Mário de Andrade, Macunatma. O herbi sem nenbum carater (ed. crítica Telê Ancona Lopez). Brasilia, CNPq, 1988, p. 255-265.

22 Davi Arrigucci Jr. "Movimentos de um leitor. Ensaio e imaginaçäo crítica em Antonio Candido", Folba de S. Paulo, 23 nov. 1991.

23 Ver, a respeito, seu artigo "Texto e história", em Haroldo de Campos. $A$ operafato do texto. São Paulo, Perspectiva, 1976, p. 13-22. 
24 Os dez primeiros títulos brasileiros, publicados em espanhol, são os seguintes: Machado de Assis, Memorias pósts de Brds Cubas, 1963 (traduçāo de A. Alatorre); Graciliano Ramos, Vidas secas, 1964 (prólogo de José Rodríguez Feo); Carolina Maria de Jesús, La fupela, 1965 (prólogo de Mario Trejo); José Luis Lins do Rego, Nino de ingenio, 1969 (prólogo de Jose Triana); Carlos Drummond de Andrade, Poemns, 1970 (prólogo de Muñoz Unsain); Machado de Assis, Varias historias, 1972 (prólogo de Antonio Benítez Rojo); Euclides da Cunha, Los sertones, 1973 (prólogo de Glauber Rocha); Jorge Amado, Gabriela, clavo y canela, 1975 (prólogo de Adolfo Martí Fuentes); Joāo Guimarães Rosa, Gran sert6n: peredas, 1979 (prólogo de Trinidad Pérez Valdés); Clarice Lispector, La pasión segrin G. H., 1982 (prólogo de Trinidad Pérez Valdés). Agradeço a informação a Silvia Gil.

25 America Latina en su literatura, p. 17.

Jorge Sclswartz é professor do departamento de Letras Modernas da Faculdade de Filosofia, Letras e Ciências Humanas da USP. 